This section looks back on a ground-breaking contribution to public health and provides a commentary on its significance from a modern perspective. To complement the theme of this month's issue, Carol W Runyan and Susan P Baker review a paper by William Haddon that was published in the Journal of Trauma in 1973.

\title{
Preventing injuries by understanding energy damage
}

\author{
Carol W Runyan ${ }^{\mathrm{a}} \&$ Susan P Baker ${ }^{\mathrm{b}}$
}

\section{"ENERGY DAMAGE AND THE TEN COUNTERMEASURE STRATEGIES}

William Haddon Jr, Journal of Trauma 1973;13:321-31.

... The fifth strategy is to separate, in space or time, the energy being released from the susceptible structure, whether living or inanimate: the evacuation of the Bikini islanders and test personnel, the use of sidewalks and the phasing of pedestrian and vehicular traffic, the elimination of vehicles and their pathways from community areas commonly used by children and adults, the use of lightning rods, and the placing of electric power lines out of reach. This strategy, in a sense also concerned with rate-of-release modification, has as its hallmark the elimination of intersections of energy and susceptible structure a common and important approach."

For the full text of the paper by W Haddon $\mathrm{Jr}^{1}{ }^{1}$ please see: doi:10.1097/00005373-197304000-00011

It is more than 35 years since William Haddon, as president of the Insurance Institute for Highway Safety in Washington, DC, published his now classic paper, "Energy damage and the ten countermeasure strategies", in the Journal of Trauma. ${ }^{1}$ This paper further developed ideas from his article published three years earlier in the American Journal of Public Health, "On the escape of tigers: an ecologic note." ${ }^{2}$ Both papers have withstood the test of more than 35 years as critical conceptual pieces in the field of injury control. In them, Haddon presents a conceptual framework that is not limited as a tool for injury prevention, but can be used successfully as a way to identify preventive interventions for almost any public health problem. ${ }^{3}$

In this work, Haddon addressed the notion that injury occurs through the transfer of energy, of which there are several types: kinetic, thermal, chemical, electrical and ionizing radiation - and that damage to the body results when energy is transferred in quantities or at rates that the body cannot withstand. He presents his analysis of how injuries occur in parallel to the way the medical world has come to understand the infectious process: through the transfer of infectious agents to the human host. Haddon stressed that this allows for a more systematic approach to prevention through the development of countermeasures that address one or more elements of the injury process.

The use and teaching of the countermeasures encourages us to be creative and consider multiple opportunities for prevention that might otherwise go unrealized, in addressing injury or other health problems. For example, the first strategy, "preventing the marshalling of the energy in the first place" challenges us to think about whether the presence of certain hazardous products or activities that we often assume are inevitable must be seen this way. By generating ideas associated with this first strategy, we might actually find ways to eliminate very basic hazards that would otherwise have been considered as inescapable. In the area of injuries, this might mean not manufacturing a dangerous product like all-terrain vehicles, certain types of handguns or dangerous toys. This thinking could be applied to considering the manufacture of cigarettes or of certain types of foods or beverages. Clearly, we need not assume that we will always have cigarettes or toys laced with lead paint. We can choose to eliminate these hazards.

In applying the remaining nine strategies, one has to think hard about the injury process and where it can be interrupted. The majority of these strategies point to changing the environment in ways that have passive influence, not requiring individuals to take direct action for preserving their own safety. As such, most will have more universal impact and protect whole populations, in the true tradition of public health practice. As with other efforts in contemporary public health to address "root causes" of health disparities, for example, Haddon's strategies encourage a more fundamental way of thinking about the processes by which injuries (or other health problems) occur and, thus, the ways by which they can be prevented. This approach is in contrast to the tendency to think only of behaviour-change strategies that have, over time, been fraught with problems and are often less effective. As the passive approaches require less individual effort, they will have more chance of success; not relying on individual knowledge, will to change, or correct and consistently applied behaviours. ${ }^{4}$

Another point that Haddon makes in his Journal of Trauma paper ${ }^{1}$ is that change can be - and must be implemented by any of several players.

\footnotetext{
a University of North Carolina Injury Prevention Research Center, University of North Carolina, 137 East Franklin Street, Chapel Hill, NC, United States of America (USA).

b Bloomberg School of Public Health, Johns Hopkins University, Baltimore, MD, USA.

Correspondence to Carol Runyan (e-mail: carol_runyan@unc.edu).
} 
Though this includes health professionals, his model generates approaches that are often more suited to engineering or architectural change and rely on policy interventions more often than on educational approaches. As such, the audience for this approach is broad.

We owe a tremendous debt to William Haddon. He was a physician trained in public health who served as a leader of the New York State Health Department and later the National Highway Traffic Safety Administration and the Insurance Institute for Highway Safety. He left an indelible mark on the development of injury control through his excellence in research on a wide array of topics from falls to ski injuries to pedestrian safety and motor vehicle occupant protection. His classic text, Accident Research, published with Edward Suchman and David Klein in 1964, assembled and critiqued major pieces of work in injury control to that date, serving as the superb first textbook of injury control. ${ }^{5}$

What is probably most significant about Haddon's conceptual work, aside from its incredible practicality, is that he has outlined a systematic way of thinking about a whole set of problems. As he points out, this is a mark of a maturing field in which processes are understood, and then that understanding is used to push forward with solutions. Our field of injury control is still maturing. Along with his classic matrix, ${ }^{6,7}$ Haddon's conceptual work in developing the 10 countermeasures laid an important and enduring foundation for continued progress. These models are universally applicable in any setting and culture or with any type of injury or health problem.

We encourage careful reading of this classic paper and the use of
Haddon's strategies in the development of approaches to injury and violence prevention worldwide. Resources are too scarce and the lost lives too precious and numerous for us to develop interventions without the benefit of clear thinking of the type Haddon's models stimulate. As we work to create a trained cadre of professionals responsible for the practice of injury control, these concepts are central-much like teaching Koch's postulates to bacteriologists or Newton's laws of physics to engineers.

Funding: This work was partially supported by funding from the National Center for Injury Prevention and Control at the United States Centers for Disease Control and Prevention.

Competing interests: None declared.

\section{References}

1. Haddon W. Energy damage and the ten countermeasure strategies. J Trauma 1973;13:321-31. PMID:4700110 doi:10.1097/00005373-19730400000011

2. Haddon W. On the escape of tigers: an ecologic note. Am J Public Health 1970;60:2229-34. doi:10.2105/AJPH.60.12.2229-b

3. Runyan CW. Back to the future: revisiting Haddon's conceptualization of injury epidemiology and prevention. Epidemiol Rev 2003;25:60-4. PMID:12940231 doi:10.1093/epirev/mxg005

4. Baker SP. Childhood injuries. The community approach to prevention. J Public Health Policy 1981;2:235-46. PMID:7298840 doi:10.2307/3342369

5. Haddon W, Suchman EA, Klein D. Accident research: methods and approaches. New York, NY; Harper and Row; 1964

6. Haddon W. Advances in the epidemiology of injuries as a basis for public policy. Public Health Rep 1980;95:411-21. PMID:7422807

7. Haddon W. Options for the prevention of motor vehicle crash injury. Isr J Med Sci 1980;16:45-68. PMID:7358516 